\title{
The influence of main parameters of regenerative heat exchanger on its energy efficiency
}

\author{
Nikolay Monarkin ${ }^{1, *}$, Anton Sinitsyn ${ }^{1}$, Mikhail Pavlov ${ }^{1}$ and Timur Akhmetov ${ }^{2}$ \\ ${ }^{1}$ Vologda State University, Institute of civil engineering, 160000 Vologda Lenina str. 15, Russia \\ ${ }^{2}$ Kazan State Power Engineering University, Kazan, Russia
}

\begin{abstract}
The influence of various parameters of stationary switching regenerative heat exchangers used for ventilation on its thermal efficiency was studied. Considered are the geometric (length, diameter and wall thickness of a single equivalent nozzle channel), thermophysical (density and heat capacity of the nozzle material) and operation (air flow through the regenerator and the time of one stage of accumulation/regeneration of thermal energy) parameters.
\end{abstract}

\section{Introduction}

In recent years, compact energy-saving devices have been used for ventilation of civil buildings as an alternative to central systems. The most energy-efficient among them are stationary switching regenerative heat exchangers (SSRHE). Such devices can decrease the high heat consumption for ventilation and provide a fairly simple solution to the problem of insufficient air exchange in some rooms [1,2].

Given the relevance of SSRHE usage for premises ventilation, an important issue is the design of such devices. In this case, first of all, it is necessary to consider a heat exchanger called a nozzle, which is the SSRHE basis. A nozzle, like any heat exchanger, must effectively transfer thermal energy between flows, and this characteristic depends on its design and material. In addition, the important SSRHE parameters are the volume of air flows through the device and the duration of their passage.

Most of the works that give recommendations on the design of ventilation heat exchangers consider devices based on recuperative heat exchangers, including rotary heat exchangers [3-5]. The existing works devoted to SSRHE do not give specific information on the most challenging design $[6,7]$. Therefore, the purpose of this paper is to determine the nature and degree of influence of changes of the main SSRHE parameters on its energy efficiency, which can be used in design of such devices.

\section{Materials and methods}

As part of SSRHE construction, the regenerative nozzle is a cylindrical bunch of longitudinal channels with a small cross-sectional size. The SSRHE operation principle consists in alternate changing of modes of external air inflow and internal air exhaust within a certain time period. In the exhaust mode, the internal warm air of room passes through the nozzle and heats it in order to transfer part of thermal energy to the outside air after switching the mode to the inflow. Thus, the device changes the stages of accumulation and regeneration of thermal energy. To induce air motion in the heat exchanger, a reversible fan is used. For effective ventilation of one or several adjacent rooms, SSRHE are installed in pairs in antiphase mode [8].

Parameters of heat exchanger (regenerator) are determined from numerical implementation of the constructed mathematical model, which describes the processes of heat transfer in a single nozzle channel [9]:

$$
\begin{aligned}
& c_{n} \cdot \rho_{n} \cdot S_{n} \cdot \frac{\partial T_{n}(z, \tau)}{\partial \tau}=\Pi \cdot \alpha \cdot\left(T_{a}(z, \tau)-T_{n}(z, \tau)\right), \\
& 0<\tau<n \cdot \tau_{0}, \quad 0<z<L \\
& G \cdot c_{a} \cdot \frac{\partial T_{a}(z, \tau)}{\partial z}+\Pi \cdot \alpha \cdot\left(T_{a}(z, \tau)-T_{n}(z, \tau)\right)+ \\
& +c_{a} \cdot \rho_{a} \cdot S_{a} \cdot \frac{\partial T_{a}(z, \tau)}{\partial \tau}=0,0<\tau<n \cdot \tau_{0}, 0<z<L \\
& T_{a}(0, \tau), \quad T_{a}(z, 0), \quad T_{n}(0, \tau), \quad T_{n}(z, 0)
\end{aligned}
$$

Equations (1) and (2) describe the temperature fields of nozzle $\left(T_{\mathrm{n}}(\mathrm{z}, \tau)\right)$ and air $\left(T_{\mathrm{a}}(\mathrm{z}, \tau)\right)$, respectively. The parameters (3) are set as the boundary conditions of the problem.

In the model (1) - (3): $G$ is the mass air flow in channel, $\mathrm{kg} / \mathrm{s} ; c_{\mathrm{n}}, c_{\mathrm{a}}$ is the mass heat capacity of nozzle and air, respectively, $\mathrm{J} /(\mathrm{kg} \cdot \mathrm{K}) ; \rho_{\mathrm{n}}, \rho_{\mathrm{a}}$ are the densities of nozzle and air, respectively, $\mathrm{kg} / \mathrm{m}^{3} ; \mathrm{P}$ is the channel perimeter, $\mathrm{m} ; S_{\mathrm{n}}, S_{\mathrm{a}}$ are the cross-sectional area of the nozzle channel and air, respectively, $\mathrm{m}^{2} ; \alpha$ is the heat transfer coefficient, $\mathrm{W} /\left(\mathrm{m}^{2} \cdot \mathrm{K}\right) ; \quad \tau_{0}=\tau_{\text {acc }}+\tau_{\text {reg }}$ is the regenerator cycle time, $\mathrm{s}$; $\tau_{\mathrm{acc}}$ is the duration of accumulation stage; $\tau_{\text {reg }}$ is the duration of regeneration stage.

"Corresponding author:nikolay-monarkin@yandex.ru 
The evaluation criterion is the dimensionless energy efficiency coefficient, which is the ratio of the actual energy used by the regenerator to the maximum possible energy for use.

$$
E_{a c c}=\frac{\delta T_{1}}{\Delta T_{\max \operatorname{reg}} \frac{\delta T_{2}}{\Delta T_{\max }}}
$$

where $\Delta T_{\max }=\left(T_{\text {in }}-T_{\text {out }}\right)$ is the maximum possible cooling or heating of air in nozzle from the internal medium temperature $T_{\text {in }}$ to the outside temperature $T_{\text {out }}$, ${ }^{\circ} \mathrm{C}$;

$\delta T_{1}$ is the cooling of internal nozzle air at the end of the accumulation phase, ${ }^{\circ} \mathrm{C}$;

$\delta T_{2}$ is the heating of outside nozzle air at the end of the regeneration phase, ${ }^{\circ} \mathrm{C}$.

The average stage performance coefficients are equal $E_{\text {acc }}=E_{\text {reg }} E$.

During operation, the following nozzle parameters are varied: the single channel diameter $(d)$, length $(l)$, thickness of single channel wall $(\delta)$, volumetric air flow rate through the nozzle $(L)$, density $\left(\rho_{\mathrm{n}}\right)$, specific isobar heat capacity $\left(c_{\mathrm{n}}\right)$. Also the time of one stage of accumulation/regeneration of thermal energy varies $\left(\tau=\tau_{\text {acc }}=\tau_{\text {reg }}\right)$.

\section{Results and discussion}

The heat transfer efficiency in regenerator is primarily affected by the contact area (heat transfer area) between air and nozzle. Consequently, the parameters of regenerator nozzle, which affect the change in heat transfer area, also affect the efficiency of regenerator. The smaller is the heat transfer area, the lower the efficiency is and vice versa.

The heat transfer area decreases when nozzle length decreases and the total number of nozzle channels is reduced. It occurs with an increase in transverse dimensions and with an increase in wall thickness of a single nozzle channel.

If the transverse dimensions of a single nozzle channel increase due to the limited overall transverse size (diameter) of nozzle, the total heat transfer area decreases, which is associated with a decrease in the total number of channels in nozzle. The overall diameter of nozzle is limited as the possible amount of through holes in outer walls is limited. In this case, the nozzle diameter is limited to $0.2 \mathrm{~m}$ (area of $0.03 \mathrm{~m}^{2}$ ).

The relationship between the energy efficiency coefficient and the equivalent diameter of a single channel is shown in Figure 1. It is seen that when diameter increases from 1.6 to $5.8 \mathrm{~mm}$ (by 3.63 times), the efficiency decreases: for a flow rate of $15 \mathrm{~m}^{3} / \mathrm{h}$ by $3 \%$, for a flow rate of $20 \mathrm{~m}^{3} / \mathrm{h}$ by $4 \%$, for a flow rate of $31 \mathrm{~m}^{3} / \mathrm{h}$ by $7 \%$, for a flow rate of $50 \mathrm{~m}^{3} / \mathrm{h}$ by $10 \%$. That is, an increase in the channel diameter with a constant air flow through the nozzle reduces its efficiency, and the sharpest decrease is observed at the maximum air flow rate.

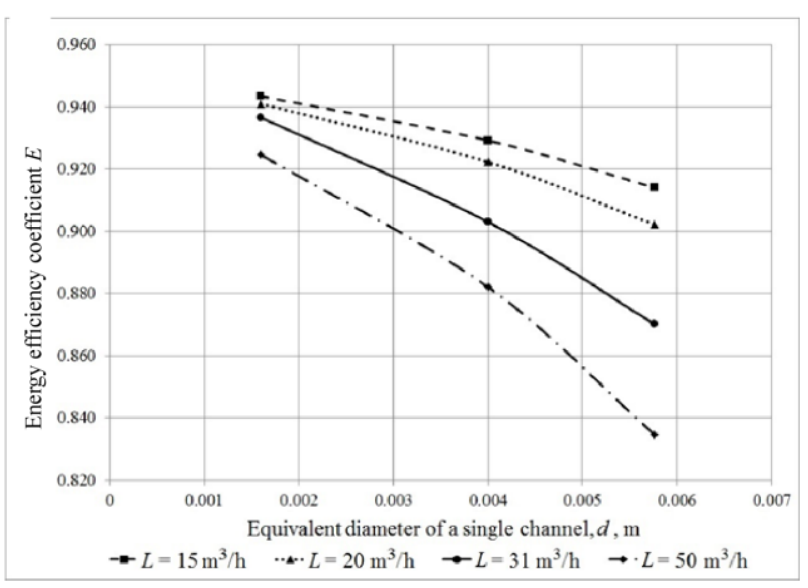

Fig. 1. The relationship between the energy efficiency coefficient $\mathrm{E}$ and the equivalent diameter of a single channel (l=0.64 m, $\delta=0.5 \mathrm{~mm}, \tau=40 \mathrm{~s}$ ).

According to Figure 2, an increase in the length of channel (nozzle) contributes to an increase in coefficient $E$. If the channel length increases from 0.2 to $0.64 \mathrm{~m}$ (by 3.2 times), then the efficiency coefficient increases by $5 \%$ for $d=1.6 \mathrm{~mm}$, by $10 \%$ for $d=4.0 \mathrm{~mm}$; by $9 \%$ for $\mathrm{d}=5.8 \mathrm{~mm}$.

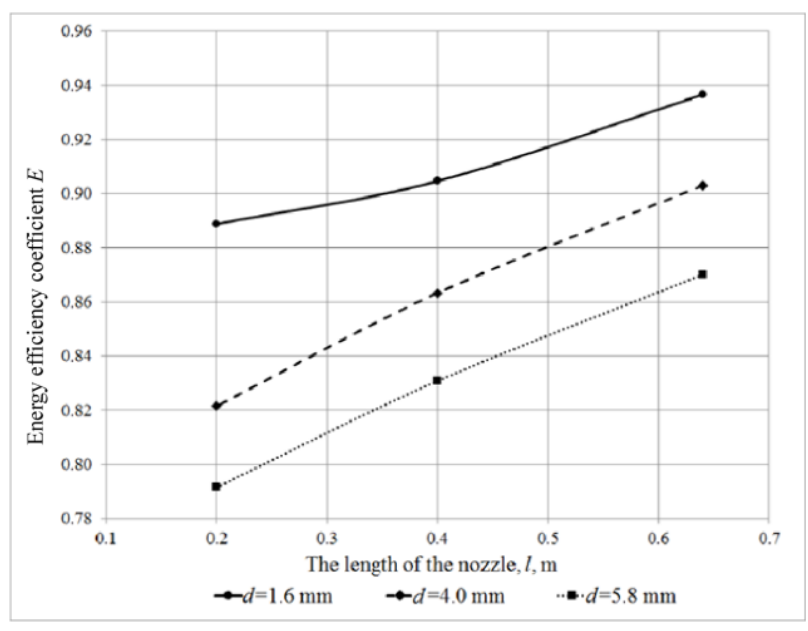

Fig. 2. The relationship between the energy efficiency coefficient $E$ and the channel length $\left(\mathrm{L}=31 \mathrm{~m}^{3} / \mathrm{h}, \delta=0.5 \mathrm{~mm}\right.$, $\tau=40 \mathrm{~s})$.

If the wall thickness of a single channel increases, the total number of nozzle channels decreases due to the larger filling of nozzle section with solid material. Thus, the smaller channel wall thickness results in a more efficient regenerator (Fig. 3). In this case wall thickness is limited only by the condition of structural strength. 


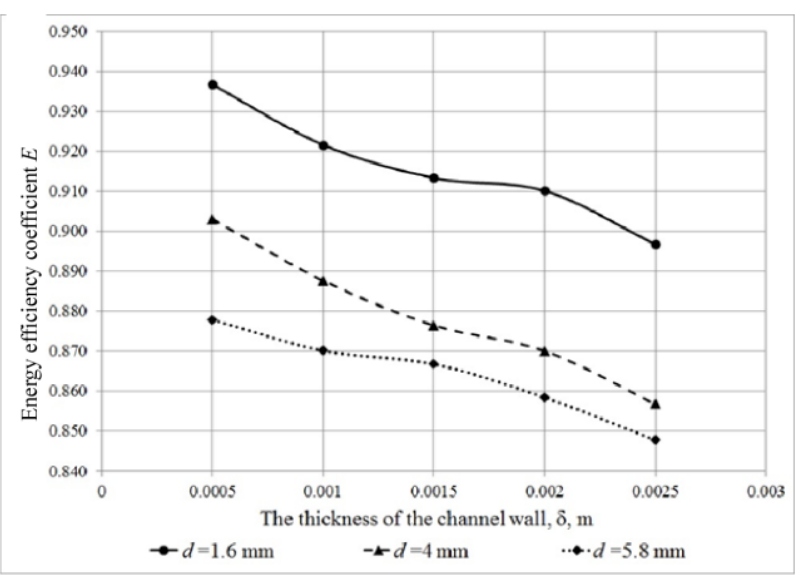

Fig. 3. The relationship between the energy efficiency coefficient $E$ and the wall thickness of a single channel for three channel diameters $\left(l=0.64 \mathrm{~m}, \tau=40 \mathrm{~s}, L=31 \mathrm{~m}^{3} / \mathrm{h}\right)$.

In general, in Figure 3, a decrease in efficiency is observed with an increase in the diameter and wall thickness of channel, and for a curve for one diameter the decrease in efficiency is weak. For diameter of 1.6 $\mathrm{mm}$, the efficiency coefficient decreases by $4 \%$, for diameter of $4.0 \mathrm{~mm}$ it decreases by $5 \%$, for diameter of $5.8 \mathrm{~mm}$ it decreases by $3 \%$.

The greater is the amount of air passing through the SSRHE per unit time, the more its efficiency decreases (Fig. 4). So, for an increase in air flow from 15 to 50 $\mathrm{m}^{3} / \mathrm{h}$ (by 3.33 times), the efficiency decreases as follows: by $2 \%$ for diameter of $1.6 \mathrm{~mm}$, by $5 \%$ for diameter of $4.0 \mathrm{~mm}$, by $9 \%$ for diameter of $5.8 \mathrm{~mm}$.

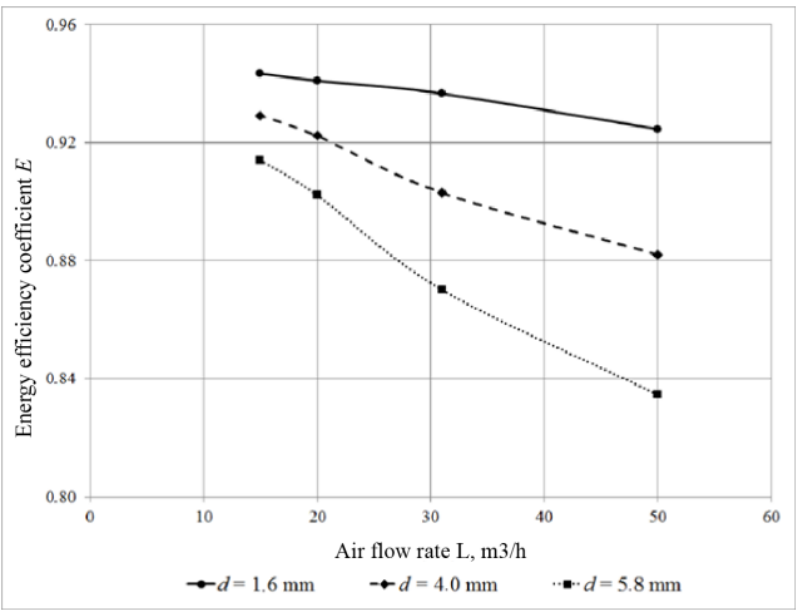

Fig. 4. The relationship between the energy efficiency coefficient $E$ and air flow rate for three channel diameters $(l=0.64 \mathrm{~m}, \tau=40 \mathrm{~s}, \delta=0.5 \mathrm{~mm})$.

An increase in time of stage of accumulation/regeneration of thermal energy in regenerator leads to a decrease in its energy efficiency (Fig. 5). Figure 5 shows that when the stage time changes from 5 to $300 \mathrm{~s}$ (by 60 times), the efficiency decreases by $3 \%$ for a length of $0.64 \mathrm{~m}$, by $6 \%$ for a length of $0.4 \mathrm{~m}$, by $9 \%$ for a length of $0.2 \mathrm{~m}$. That is, in the worst conditions there exists an option with a minimum length and maximum stage time. And it is worth noting that for a decrease in length with a constant diameter, the regenerator efficiency decreases.

Figure 6 shows the relationship between the efficiency coefficients and the density of the nozzle material for three different air flow rates at constant heat capacity (channel length $l=0.64 \mathrm{~m}$, diameter $d=4.0 \mathrm{~mm}$, wall thickness $\delta=0.5 \mathrm{~mm}$ ). The figure shows that behavior of efficiency coefficients is the same for all three flow rates: there is a noticeable increase in the beginning (from 500 to $2000 \mathrm{~kg} / \mathrm{m}^{3}$ ), then the process is practically stabilized. When the density of nozzle increases from 500 to $4000 \mathrm{~kg} / \mathrm{m}^{3}$, the efficiency coefficient increases by $1-2 \%$ for all these flow rates.

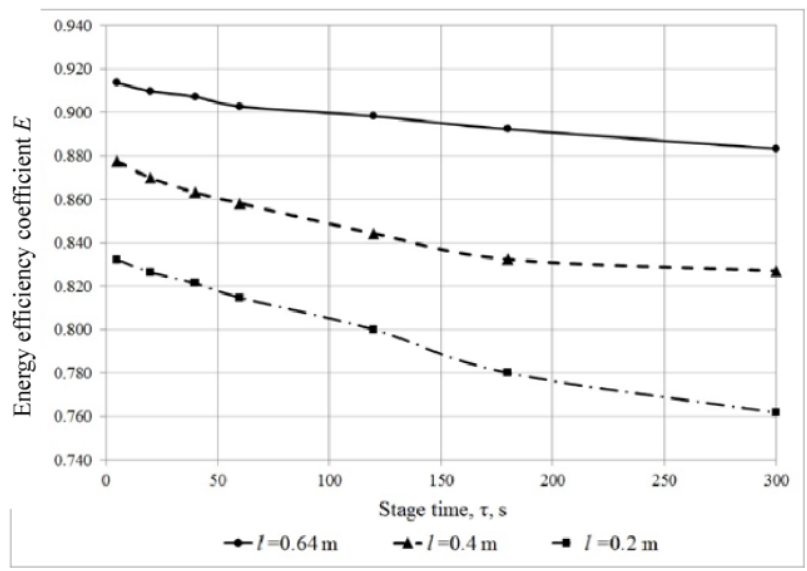

Fig. 5. The relationship between the energy efficiency coefficient $E$ and the time of one stage of accumulation/regeneration for various channel lengths ( $d=4.0$ $\mathrm{mm}, \delta=0.5 \mathrm{~mm}, L=31 \mathrm{~m}^{3} / \mathrm{h}$ )

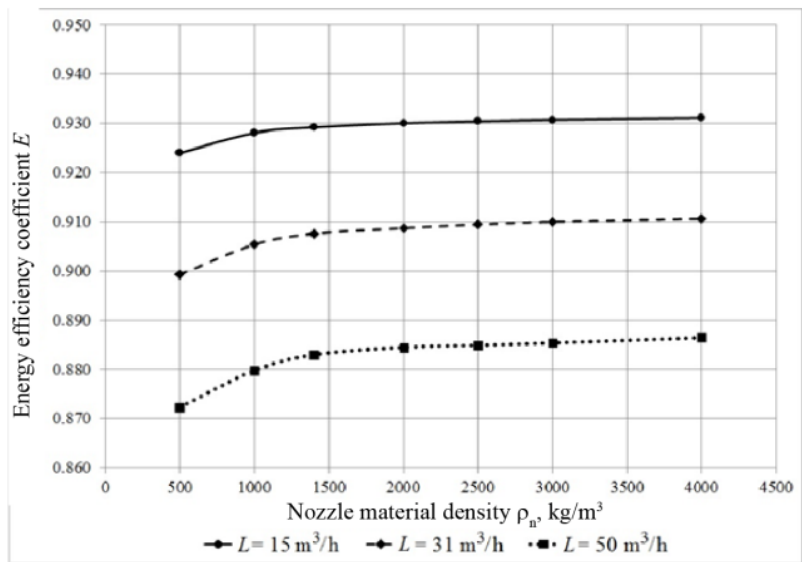

Fig. 6. The relationship between the energy efficiency coefficient $E$ and the nozzle material density $(d=4.0 \mathrm{~mm}$, $l=0.64 \mathrm{~m}, \delta=0.5 \mathrm{~mm}, \tau=40 \mathrm{~s}$ ).

Variation in heat capacity at a constant density of nozzle material of $1400 \mathrm{~kg} / \mathrm{m}^{3}$ gives similar results (Fig. 7). With an increase in the heat capacity of nozzle from 1000 to $4000 \mathrm{~J} /(\mathrm{kg} \cdot \mathrm{K})$, the efficiency coefficient increases for all these flow rates by $1-2 \%$. 


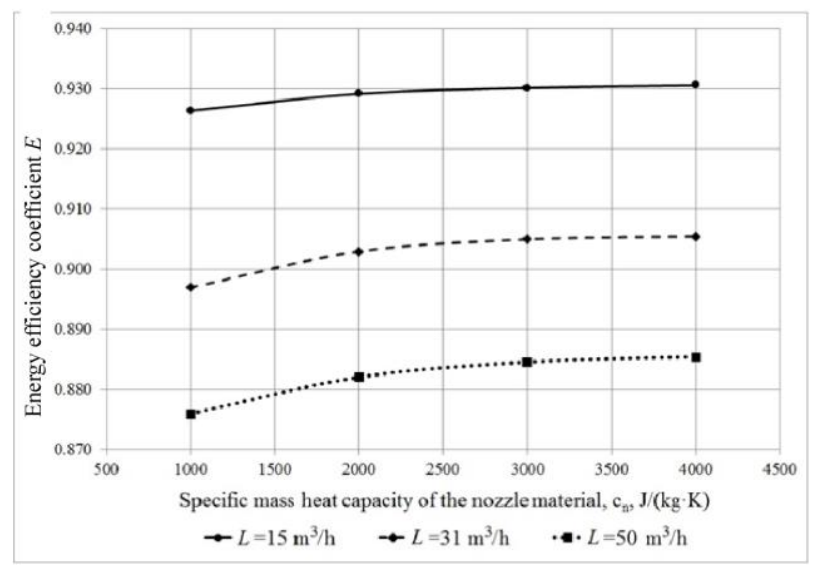

Fig. 7. The relationship between the energy efficiency coefficient $E$ and the heat capacity of nozzle material ( $d=4.0$ $\mathrm{mm}, l=0.64 \mathrm{~m}, \delta=0.5 \mathrm{~mm}, \tau=40 \mathrm{~s}$ ).

\section{Conclusions}

The performed studies show that the diameter and length of a single nozzle channel, as well as the air flow rate through nozzle, have a decisive influence on the energy efficiency of regenerator. When diameter increases from 1.6 to $5.8 \mathrm{~mm}$ (by 3.63 times), the efficiency decreases by $3-10 \%$ for the range of air flow rates of $15-50 \mathrm{~m} 3 / \mathrm{h}$. With an increase in the channel length from 0.2 to 0.64 $\mathrm{m}$ (by 3.2 times), the efficiency increases by $5-10 \%$ in the same range of air flow rates. The increase in air flow rate from 15 to $50 \mathrm{~m} 3 / \mathrm{h}$ (by 3.33 times) reduces $\mathrm{E}$ by a maximum of $9 \%$. The wall thickness of a single channel weakly affects the efficiency.

To obtain significant changes in efficiency when varying the time of one stage of accumulation/regeneration of thermal energy, its increase or decrease should be too strong, which in this case is unacceptable. Therefore, we can assume that the stage time slightly affects the regenerator efficiency.

An increase in density by 8 times and heat capacity by 4 times increase $\mathrm{E}$ by only $2 \%$, which allows us to consider the change in these parameters as insignificant.

Thus, the presented study allows one to determine the degree of influence of the listed parameters on the energy efficiency of SSRHE. It also determines the ranges of optimal parameters that can be used in designing.

\section{References}

[1] A.L. Naumov, S.F. Serov, A.O. Budza, HVAC: Ventilation, Heating, Air Conditioning, Heat Supply and Building Thermal Physics, 1 (2012).

[2] N. Monarkin, S. Lukin, Yu.M. Anurov, B.A. Tihomirov, G.A. Agasiants, S.M. Galileev, T.R. Akhmetov, IOP Conf. Series: Earth and Environmental Science, 337 (2019).

[3] V.V. Nemirovskaya, A.V. Kuzovlev, Scientific journal of NRU ITMO. Series: Refrigeration and air conditioning 2 (2015).
[4] M.N. Stepanenko, A.Ya. Shelginsky, Reliability and safety of energy 2, 25 (2014).

[5] M.R. Nasr, M. Fauchoux, R.W. Besant, C.J. Simonson, Renewable and Sustainable Energy Reviews 30 (2014).

[6] V.A. Vasiliev, A.I. Gavrilov, K.K. Kamenetsky, E.V. Sobol', Bulletin of the International Academy of Refrigeration 1 (2010).

[7] A.E. Aleshin, A.V. Tsygankov, Bulletin of the Dagestan State Technical University. Technical science 2 (2016)

[8] N.N. Monarkin, S.V. Lukin, A.A. Kochkin, BST: Bulleten' stroitel'noy tehniki 6, 1018 (2019).

[9] N.N. Monarkin, S.V. Lukin, A.A. Kochkin, Volga Scientific Journal 3, 47 (2018). 